\title{
- Characterisation of a myocardial infarction biomarker, brain-type natriuretic peptide, as a biomarker of cognitive dysfunction
}

\author{
(DEdin Begic $*$, \\ DSuncica Hadzidedic', \\ (D)Ajla Kulaglic', \\ (Delma Ramic-Brkic', \\ (DZijo Begic ${ }^{2}$, \\ DMirsada Causevic ${ }^{1}$ \\ 'Sarajevo School of Science \\ and Technology, Sarajevo, \\ Bosnia and Herzegovina \\ 2University Clinical Center \\ Sarajevo, Sarajevo, Bosnia \\ and Herzegovina
}

KEYWORDS: natriuretic peptides, brain natriuretic peptide, biomarker of myocardial infarction, Alzheimer's disease.

CITATION: Cardiol Croat. 2018;13(11-12):435. | https://doi.org/10.15836/ccar2018.435

*ADDRESS FOR CORRESPONDENCE: Edin Begic, Sarajevo School of Science and Technology, Sarajevo Medical School, Department of Pharmacology, Hrasnicka cesta 3a, 71000 Sarajevo, Bosnia and Herzegovina. /

Phone: +38761303375 / E-mail: edinbegic90@gmail.com

ORCID: Edin Begic, https://orcid.org/0000-0001-6842-262X • Suncica Hadzidedic, https://orcid.org/0000-0001-9026-8737 Ajla Kulaglic, https://orcid.org/0000-0003-3410-7079 • Belma Ramic-Brkic, https://orcid.org/0000-0002-8205-0137 Zijo Begic, https://orcid.org/0000-0002-1863-5755 • Mirsada Causevic, https://orcid.org/0000-0002-6099-6415

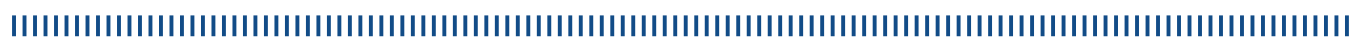

Introduction: Presence of a cardiovascular disorder may contribute to poor cognitive aging and Alzheimer's disease (AD)type cognitive decline. $\mathrm{AD}$ is the most prevalent age-related neurodegenerative disease which is prominently characterised by progressive loss of cognitive abilities for which specific and sensitive biomarkers and disease-modifying therapies are lacking. ${ }^{1-3}$ Brain-type natriuretic peptide (BNP) and N-terminal pro-brain natriuretic peptide (NT-proBNP) are the most important humoral indicators of cardiac dysfunction and heart failure, and their level in blood is proportional to the degree of myocardial function failure. In an effort to identify key biomarker(s) of AD, from an easily accessible biological fluid, such as blood, that would aid in early diagnosing and/or monitoring of a progression of AD, plasma levels of BNP were examined in subjects with differing cognitive abilities.

Materials and Methods: Human subjects were recruited for the European Union-funded AddNeuroMed biomarker project through medical centres based in several countries (UK, Finland, Italy, Greece and Poland). BNP levels in the subjects' plasma samples were measured using Slow Off-rate Aptamer (SOMAmer)-based capture array called SOMAscan (SomaLogic, Inc., CO, USA). BNP measurements from the AddNeuroMed subjects were obtained from the Synapse Data Platform which is hosted by Sage Bionetworks (https://www.synapse.org).

Results: Plasma BNP levels were compared between two groups of subjects: 1) healthy subjects (N=189), and 2) subjects diagnosed with probable Alzheimer's-type dementia ( $N=308)$. Our analysis shows that subjects diagnosed with probable AD have significantly lower BNP levels $(2986.82 \pm 238.82)$ compared to healthy controls $(3041.98 \pm 236.67)(U=24935.00, Z=-2.68, p=$ 0.007).

Conclusions: Decreased plasma levels of an established cardiovascular biomarker, BNP, as measured by a novel technology termed SOMAscan, appear to associate with declining brain health. Our results warrant further investigations into a role of $\mathrm{BNP}$ in $\mathrm{AD}$ and they have implications for a wider population as they are related to a research cohort that consisted of subjects who were recruited from a wider geographic area (several European countries).
RECEIVED:

August 26, 2018

ACCEPTED:

November 5, 2018

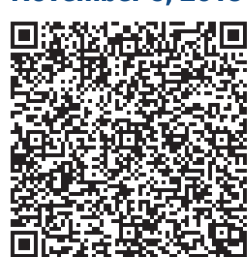

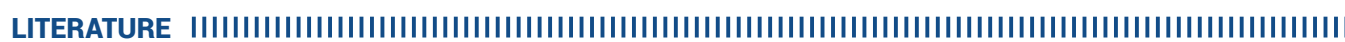

1. Picano E, Bruno RM, Ferrari GF, Bonuccelli U. Cognitive impairment and cardiovascular disease: So near, so far. Int J Cardiol. 2014 Jul 15;175(1):21-9. https://doi.org/10.1016/j.ijcard.2014.05.004

2. Sattlecker M, Kiddle SJ, Newhouse S, Proitsi P, Nelson S, Williams S, et al. Alzheimer's disease biomarker discovery using SoMAscan multiplexed protein technology. Alzheimer's Dement. 2014 Nov;10(6):724-34. https://doi.org/10.1016/j.jalz.2013.09.016

3. Kiddle SJ, Sattlecker M, Proitsi P, Simmons A, Westman E, Bazenet C, et al. Candidate Blood Proteome Markers of Alzheimer's Disease Onset and Progression: A Systematic Review and Replication Study. J Alzheimers Dis. 2014;38(3):515-31. https://doi.org/10.3233/JAD-130380 